\title{
Burden of Hepatitis C on Patients with Thalassemia
}

\author{
Zahra Sepehri, ${ }^{1}$ and Seyed Moayed Alavian ${ }^{2, *}$ \\ ${ }^{1}$ Department of Internal Medicine, Zabol University of Medical Sciences, Zabol, IR Iran \\ ${ }^{2}$ Baqiyatallah Research Center for Gastroenterology and Liver Diseases (BRCGL), Baqiyatallah University of Medical Sciences, Tehran, IR Iran \\ "Corresponding author: Seyed Moayed Alavian, Baqiyatallah Research Center for Gastroenterology and Liver Diseases (BRCGL), Baqiyatallah University of Medical Sciences, \\ Tehran, IR Iran. Tel: +98-2181264070, E-mail: alavian@thc.ir
}

Received 2016 August 09; Accepted 2016 August 10.

Keywords: Hepatitis C, Thalassemia

\section{Dear Editor,}

We read with interest the recently published article by Yousefi et al. (1) in your journal. Control of Hepatitis C virus (HCV) infection has been amongst our priorities in Iran and most individuals are evaluated for HCV infection and treated as well $(2,3)$. However, we found some points that need further clarification. First of all, the authors claimed that 13 (8.5\%) of 152 patients with thalassemia were antiHCV antibody positive, however we would like to mention that antibody positivity is not correlated with infectivity, and confirmation with HCV RNA molecular study is necessary for this conclusion. History of therapy with antiviral drugs was missing in the study while there should be approximately 50\% response to pegylated-base and ribavirin therapy, according to our experience (4). They mentioned that 65 patients with thalassemia and hemophilia received blood transfusion before 1995 and 87 patients after this time. The rate of HCV infection before 1995 was significantly higher than the following years. We think that the word "hemophilia" was a kind of typing error. We agree strongly with the authors about the decreasing burden of HCV infection after 1995, time of blood screening for HCV infection in Iran.

\section{References}

1. Yousefi M, Dehesh MM, Ebadi M, Dehghan A. The prevalence of hepatitis $\mathrm{C}$ virus infection in patients with thalassemia in Zabol city of Iran. Int $J$ Infect. ;In Press(In Press):37009.

2. Tabatabaei SV, Alavian SM, Keshvari M, Behnava B, Miri SM, Karimi Elizee $P$, et al. Low dose ribavirin for treatment of hepatitis $C$ virus infected thalassemia major patients; new indications for combination therapy. Hepat Mon. 2012;12(6):372-81. doi:10.5812/hepatmon.6592. [PubMed: 22879826].

3. Alavian SM, Tabatabaei SV, Lankarani KB. Epidemiology of HCV infection among thalassemia patients in eastern mediterranean countries: A quantitative review of literature. Iran Red Cres Med J. 2010;12(4):36576.

4. Aminizadeh E, Alavian SM, Akbari Sari A, Ebrahimi Daryani N, Behnava B. Safety and Efficacy of Adding Ribavirin to Interferon or Peginterferon in Treatment of Hepatitis C Infection in Patients With Thalassemia: A Systematic Review on Randomized Controlled Trials. Hepat Mon. 2016;16(3):ee28537. doi: 10.5812/hepatmon.28537. [PubMed: 27226796]. 